\title{
Analysis of Female Breast Biopsies in Usmanu Danfodiyo University Teaching Hospital (UDUTH) Sokoto, Nigeria; A Ten Year Retrospective Study.
}

\author{
Isah $\mathrm{RT}^{1}$, Sahabi $\mathrm{SM}^{2}$, Muhammad $\mathrm{AT}^{1}$, Okechi OO${ }^{3}$, Mohammed $\mathrm{OM}^{1}$ \\ ${ }^{1}$ Histopathology Department, Faculty of Medical Laboratory Science, Usmanu Danfodiyo University, Sokoto. \\ ${ }^{2}$ Histopathology Department UDUS/UDUTH, Sokoto. \\ ${ }^{3}$ College of Medicine and Health Sciences, Abia State University, Uturu.
}

\begin{abstract}
Background: Breast cancer is one of the most important tumours affecting women in Nigeria and all over the world, with high morbidity and mortality if detection is delayed.

Objectives: This study was carried out to review the histology of all breast biopsies sent to Histopathology Laboratory in UDUTH.

Method: Using haematoxylin and eosin staining method, breast biopsies received from January 2002 to December 2011 were analyzed. Demographic data such as age, sex, site of the biopsy of all the patients were obtained through histology request card and biopsy registers.

Result: A total of 788 breast samples were received during the period under review, 403 samples (51.1\%) were benign lesions, 256 samples (32.5\%) malignant lesions and 61 samples (7.7\%) are inflammatory lesions. The age group with the highest occurrence of breast pathology is 20-29 years which are mostly benign lesions, with 50-59 years age group having the highest occurrence of malignant lesions.

Conclusion: The study indicated that most breast lesions occurring in the first three decades of life are benign, while those in the elderly are mostly malignant. We recommend strong awareness among the populace to encourage early detection of these lesions.
\end{abstract}

\section{Introduction}

Breast comprises a branching system of ducts leading down from the nipple ending in glands in which the acini aggregated into lobules. There are approximately 12 large ducts which emerge from the breast at the nipple as lactiferous ducts. These ducts then branch repeatedly giving rise to the terminal duct lobular units (TDLUs) at the end (1).

Due to hormonal changes in female most especially from the age of adolescence to menopause, breast is often prone to a lot of structural changes leading to breast pathology. Factors ranging from genetic, viruses, endocrine, geographic, reproductive function, radiation, obesity, trauma and microorganisms have been implicated as predisposing agents of breast pathology $(2,3,4)$. Breast pathology has been grouped into 3 main groups, namely inflammatory, benign and malignant lesions. The diagram below is showing normal breast anatomy and anatomical location of common breast lesions:

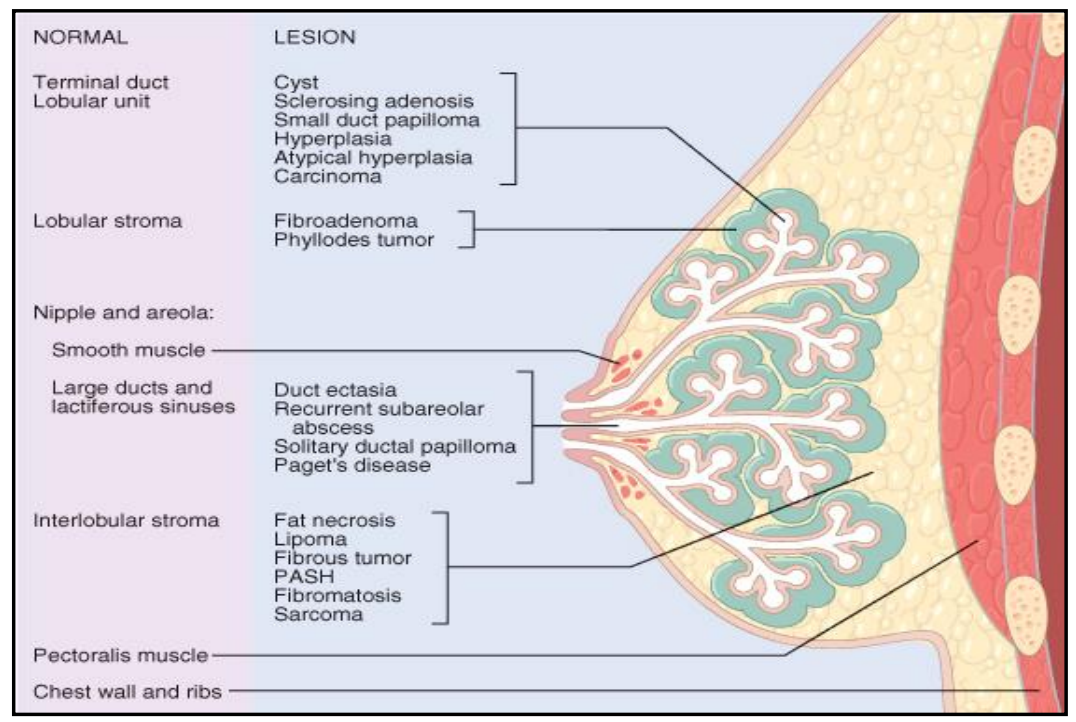


Acute and chronic inflammations are the 2 types of inflammation seen in breast biopsies, mostly caused by either microorganisms or obstruction of lactiferous ducts (5). Benign lesion is a non-cancerous tumour confined in one place and does not spread to other parts of the body. Benign lesions can be categorized into various fibrocystic changes that can be proliferative or non-proliferative changes, fibroadenoma, duct papilloma, phylloides tumour and others. These types of lesions commonly occur in women within the reproductive age mostly below 30years and have fibroadenoma as the highest occurring type (6). Malignant lesion is a cancerous condition of the breast that can invade tissues around the breast and has tendency of spreading to other parts of the body. Carcinoma of the breast can be divided according to it is origin, example; ductal and lobular or according to invasiveness example; invasive and non-invasive. Carcinoma of the breast mostly occurred after 40years of age, uncommon below 30 and rare before 25years with invasive ductal carcinoma being the highest occurring type $(5,7)$

At present, breast cancer is the most common malignancy in women around the world. It is second only to lung cancer as a cause of cancer death among women in United States. Every single woman is at risk of developing cancer with a life time risk of occurrence presently $6.5 \%$ or 1 in 15 ratios. In 2001 alone, a total of 200,000 cases were said to be diagnosed in the United States with over 40,000 dying of the disease (8). Cancer of the breast is becoming more frequent in developing countries including Nigeria, in fact it was the commonest malignancy seen in women in this country from 1990 to 1996. In a research conducted in UCH Ibadan, breast cancer has accounted for $29.7 \%$ of 818 cases of cancer in their cancer registry (9).

\section{Materials And Method}

This is a retrospective study of all breast biopsies seen in Usmanu Danfodiyo University Teaching Hospital Sokoto over a 10 year period (January 2002 - December 2011). Demographic data such as age, sex and site of the biopsy were obtained from the patients' histology request card and histology registers. Stained haematoxylin and eosin slides were retrieved and reviewed, where slides were not traced, their paraffinized blocks were traced, recut and stained using the same haematoxylin and eosin staining method and reviewed for confirmation.

The result was analyzed using SPSS statistical package.

\section{Result}

A total of 788 breast samples representing (7.1\%) of 11,106 samples received during the period under review. There were $403(51.1 \%)$ benign lesions, $256(32.5 \%)$ malignant lesions, $61(7.7 \%)$ inflammatory lesions and $68(8.6 \%)$ normal ones. The below chart is showing percentage occurrence of normal and various breast lesions:

\section{CHART 1}

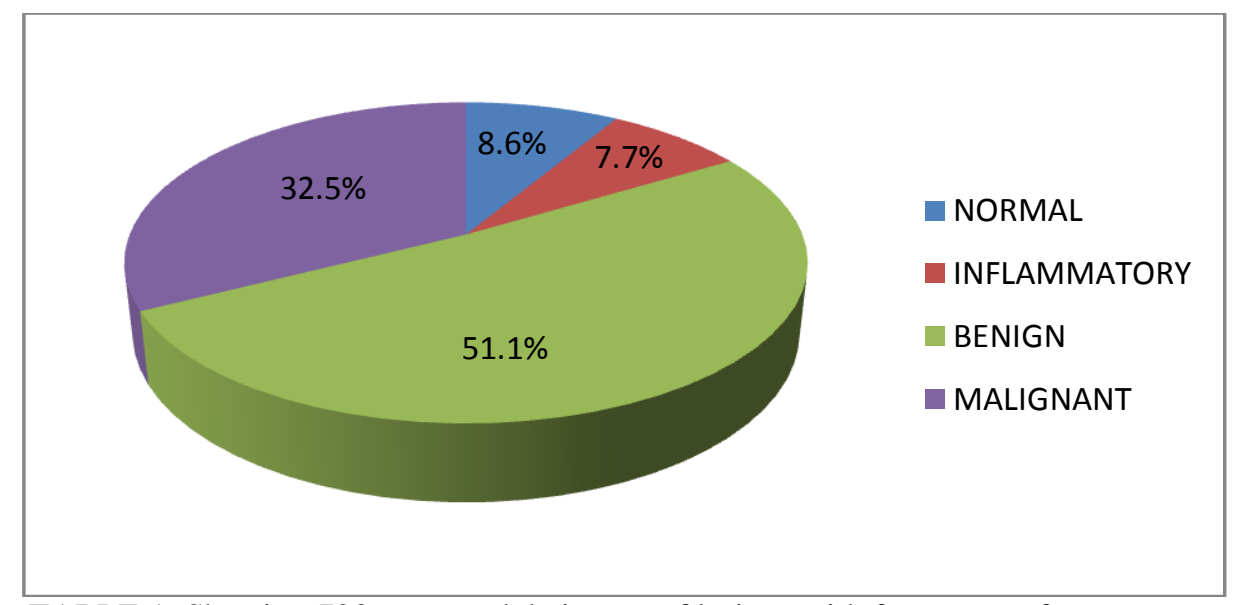

TABLE 1: Showing 720 cases and their type of lesions with frequency of occurrence.

\begin{tabular}{|l|l|l|}
\hline Type & Frequency & Percentage \\
\hline Inflammation & & \\
\hline Acute & 13 & 21.3 \\
\hline Chronic & 48 & 78.7 \\
\hline Total & $\mathbf{6 1}$ & $\mathbf{1 0 0}$ \\
\hline & & \\
\hline Benign lesion & & \\
\hline Fibroadenoma & 217 & 58.8 \\
\hline Fibrocystic disease & 71 & 17.6 \\
\hline
\end{tabular}




\begin{tabular}{|l|l|l|}
\hline Phylloides tumour & 22 & 5.5 \\
\hline Sclerosing adenosis & 10 & 2.5 \\
\hline Fibroadenosis & 5 & 1.2 \\
\hline Lactating adenoma & 8 & 2.0 \\
\hline Tubular adenoma & 7 & 1.7 \\
\hline Miscellaneous & 63 & 15.6 \\
\hline Total & $\mathbf{4 0 3}$ & $\mathbf{1 0 0}$ \\
\hline & & \\
\hline Malignant Lesion & & 76.2 \\
\hline Invasive ductal carcinoma & 195 & 4.3 \\
\hline Invasive lobular carcinoma & 11 & 3.1 \\
\hline Medullary carcinoma & 8 & 16.4 \\
\hline Miscellaneous & 42 & $\mathbf{1 0 0}$ \\
\hline Total & $\mathbf{2 5 6}$ & \\
\hline
\end{tabular}

Miscellaneous in benign lesions include lipoma, atypical lesion, intraductal papilloma, fibroepithelial polyps, lobular adenosis, duct ectasia, duct adenosis, reactive lymphoid hyperplasia and others.

Miscellaneous in malignant lesions include infiltrating lobular carcinoma, metastatic melanoma, invasive ductal papilloma, malignant fibrous histiocytoma, papillary carcinoma, mucinous carcinoma, cystosarcoma phylloides, colloid carcinoma, undifferentiated carcinoma and Paget's disease.

Out of the inflammatory lesions, 13 cases (21.3\%) are acute while 48 cases (78.7\%) are chronic. In the benign lesions, fibroadenoma is the highest occurrence with 217 cases (58.8\%) followed by fibrocystic changes 71 cases $(17.6 \%)$ and benign phylloides tumour 22 cases (5.5\%). Invasive ductal carcinoma with 195 cases $(76.2 \%)$ is the highest occurrence in malignant lesions followed by the invasive lobular carcinoma 11 cases $(4.3 \%)$ and medullary carcinoma 8 cases $(3.1 \%)$.

The age group with the highest breast pathology is 20-29years which are mostly benign with 251 cases followed by $30-39$ years with 110 cases and 10-19years with 117 cases. This will be shown by the table below:

TABLE 2: showing age range, number of breast biopsies and corresponding lesions

\begin{tabular}{|l|l|l|l|}
\hline Age range & Inflammatory & Benign & Malignant \\
\hline $0-9$ & 1 & 4 & 0 \\
\hline $10-19$ & 9 & 106 & 2 \\
\hline $20-29$ & 26 & 215 & 10 \\
\hline $30-39$ & 18 & 39 & 53 \\
\hline $40-49$ & 7 & 20 & 61 \\
\hline $50-59$ & 0 & 11 & 70 \\
\hline $60-69$ & 0 & 5 & 47 \\
\hline $70-79$ & 0 & 2 & 12 \\
\hline $80-89$ & 0 & 1 & \\
\hline Total & 61 & 403 & 2 \\
\hline
\end{tabular}

In respect of cancer occurrence within age-range, 50-59years age group has the highest occurrence of malignant lesions with 70 cases followed by $40-49$ years with 61 cases and $60-69$ years with 47 cases. The below graph is representing cancer occurrence according to age range:

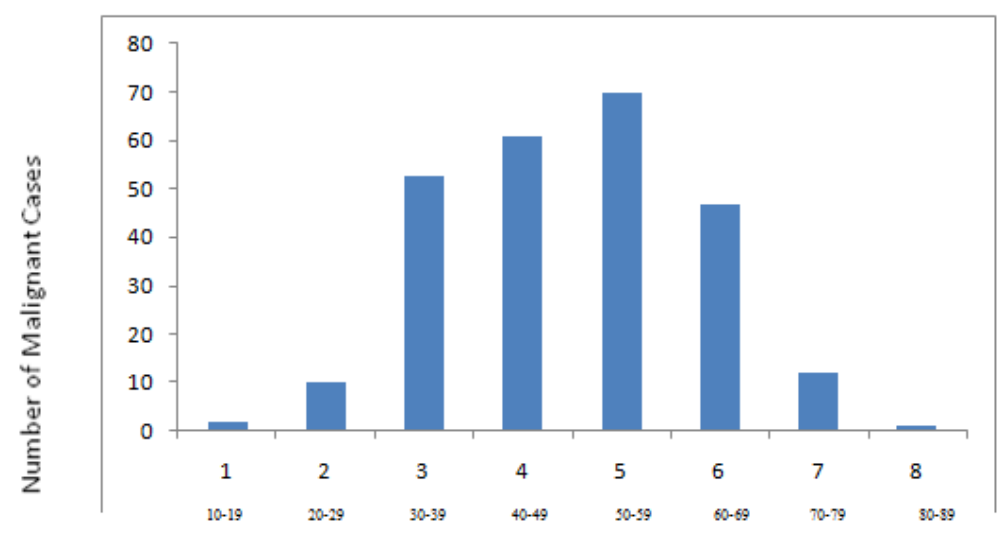

Age Ranges 


\section{Discussion}

In this 10year retrospective study, a total of 788 breast samples were received during the period under review. There were 403 cases (51.1\%) of benign lesions, 256 cases (32.5\%) of malignant lesions and 61 cases (7.7\%) of inflammatory lesions. This has clearly indicated that benign lesions are the most occurrences in our society followed by malignant lesions and then less occurring inflammatory ones. This is similar to Northeastern of Nigeria pattern in Gombe (15) and is also agreed by Kumar et al (6) and Goodman (10) literatures. Our result is in contrast to northern region of Saudi Arabia were they has least occurrence of malignant lesion than the inflammatory lesions (16). Our inflammatory cases (7.7\%) are within similar range with that of Ile-ife which has $7.2 \%$ of inflammatory lesions. Inflammation of the breast otherwise known as mastitis on the whole is uncommon and consists of only relatively few forms of acute and chronic inflammatory diseases. As there were 13 cases $(21.3 \%)$ of acute and 48 cases $(78.7 \%)$ of chronic inflammation, therefore the inflammation we have in Sokoto is more of chronic than acute one.

Fibroadenoma is the most commonly occurring benign tumour, out of 403 cases, 217 cases (58.8\%) are fibroadenomas. This finding is in keeping with similar type of breast lesion researches conducted in Nigeria and beyond $(15,16,17,18)$. This was also agreed by Robinson, Kumal et al, Olusola, Page and Sparkman literatures respectively $(2,6,9,11,12)$. Black women tend to develop fibroadenomas more frequently and at earlier age than white women (13). Fibroadenoma tend to occur more within the age range of 20-29years. Fibrocystic disease is second commonest benign lesion with 71 cases $(17.6 \%)$ in our society which is also the same in north-east, south-east and south-west of Nigeria $(15,17,18)$. Benign phylloides tumour is also common in our society with 22 cases (5.5\%), the other less commonly occurring ones are grouped as miscellaneous.

There were 256 cases $(32.5 \%)$ of malignant lesion; the mean age was 50 while the youngest was 19 and the oldest age being 80 . Virtually all invasive breast cancers are adenocarcinomas either ductal with highest occurrence or lobular $(6,12)$. This is true of our result in which we have 195cases $(76.2 \%)$ of invasive ductal carcinoma which is also the most common type of malignant lesion in our setting. This is also the same pattern obtained in various parts of Nigeria and rest of the world $(2,5,6,8,9,15,16,17,18)$. Invasive lobular carcinoma with 11 cases $(4.3 \%)$ and Medullary carcinoma with 8 cases $(3.1 \%)$ were second and third most commonly carcinomas in our locality which is also similar in Maiduguri (19). Others that are less commonly occurring are grouped under miscellaneous.

Breast cancer risk is strongly related to age, with more percentage of cases occurring in women over $50 y e a r s$ old (14). The highest number of cases of breast cancer diagnosed is in the 50-59 age groups with 70 cases out of 256 cases of cancer.

\section{Conclusion}

Most breast tumours occur in the first three decades of life and majority are benign but most tumours in the elderly are malignant. The average rate of breast pathology in our society is $7.1 \%$ with fibroadenoma and invasive ductal carcinoma been the most common benign and malignant lesions respectively. It is therefore important that strong awareness among the populace is instituted to improve presentation of these lumps early for proper health management.

\section{References}

[1]. Bentley, G. R. (2001). The evolution of the breast. American Journal of Physical Anthropology 32 (38).

[2]. Robinson, R.B. (1971). Current trends in Management of Breast Cancer. Maryland (USA): Johns Hopkins University Press.

[3]. Wohlfart, J. (1999). Reproductive risk factors for Breast cancer receptor status, Histology and Location. International Journal of Cancer 81 (1).

[4]. Nagata, C., Kawakami, N. and Shimizu, H. (1997). Trends in the incidence rate and risk factors of Breast Cancer in Japan: Breast Cancer Retreat 44(1), p.75-85.

[5]. Muhammad, M. (2001). Short Textbook of Pathology. $3^{\text {rd }}$ edition. Karachi (Pakistan): Journal Publishers.

[6]. Kumar, V., Abbas A.K., Fausto, N. (2004). Robbins and Cotran Pathologic basis of disease. $7^{\text {th }}$ edition. India: Elsevier, a division of Reed Elsevier India Private Ltd.

[7]. Bodian, C.A. (1993). Prognostic significance of Proliferative Breast Diseases, 71-3896.

[8]. Michael, R. (2007). Breast Cancer Information (online): http//www.google.com/search.

[9]. Olusola, D. (2011). Lecture notes on tumours of the Breast and Cervix.

[10]. Goodman, M.T. (2006). Comparative Epidemiology of Breast Cancer among men and women in USA, 17(2).

[11]. Page, D.L. (1988). Diagnostic Histopathology of Breast. New stone.

[12]. Sparkman, R.S. (1962). Reliability of frozen section in the Diagnosis of Breast Lesions. Ann Surg: 155,924

[13]. Health line. (2007). Breast Tumours (online): http//www.healthline.com/fibroadenoma.

[14]. Cancer Research (2012). Adenocarcinomas (online): http//www.cancerresearchuk.org/glossary.

[15]. Mayun, A.A., Pindiga,U.H., Babayo, U.D. (2008). Pattern of Histopathological Diagnosis of Breast Lesions in Gombe, Nigeria: PubMed $17(2) ; 159-62$

[16]. Chiedozi, L.C., El-Hag, I.A., Kollur, S.M. (2002). Breast Diseases in the Northern region of Saudi Arabia.

[17]. Adeniji, K.A., Adelusola, K.A., Odesanmi, W.O. (2008). Benign Disease of the Breast in Ile-Ife: A 10 year experience and literature review.

[18]. Anyikam, A., Nzegwu, M.A., Ozumba, B.C. (2005). Benign Breast Lesions in Eastern Nigeria.

[19]. Mayun, A.A., Obiano, S.K., Shehu, S.K., Abdulazeez, J.O. (2008). Breast Malignancies in a tertiary health setting in North-eastern Nigeria: a histopathological review. 